\title{
Lack of Correlation Between Immunohistochemical Expression of SPARC and Invasion in Different Grades of Meningiomas
}

\author{
HARCHARAN K. ROOPRAI ${ }^{1 *}$, ANDREW J. MARTIN ${ }^{2 *}$, ANDREW KING ${ }^{3}$, USHA D. APPADU ${ }^{1}$, \\ RICHARD W. GULLAN ${ }^{1}$, NICK W.M. THOMAS ${ }^{1}$ and GEOFFREY J. PILKINGTON ${ }^{4,5}$ \\ ${ }^{1}$ Department of Neurosurgery, King's College Hospital, London, U.K.; \\ ${ }^{2}$ Department of Neurosurgery, St George's Hospital, London, U.K.; \\ ${ }^{3}$ Department of Clinical Neuropathology, King's College Hospital, London, U.K.; \\ ${ }^{4}$ School of Pharmacy and Biomedical Sciences, University of Portsmouth, Portsmouth, U.K.; \\ ${ }^{5}$ Department of Basic and Clinical Neuroscience, King's College London, London, U.K.
}

\begin{abstract}
Background: Grade I meningiomas are generally benign and non-invasive whereas Grade II (atypical) and Grade III (malignant) meningiomas tend to be invasive with a high risk of recurrence. SPARC, secreted protein, acidic and rich in cysteine, is a multifunctional glycoprotein which has been proposed to be a potential diagnostic marker of invasive meningiomas. There has been increased reporting of atypical meningiomas since the current World Health Organization (WHO) included brain invasion as a grading criterion for classification of these particular meningiomas. Materials and Methods: The aim of this study was to re-evaluate any correlation between immunohistochemical expression of SPARC in 34 meningiomas of various grades using the current classification (2016). We had previously classified these cases using the 2002 WHO criteria. Results: There is no correlation between expression of SPARC and invasion in different grades of meningioma. Conclusion: SPARC does not appear to be a good predictor of invasion in meningiomas.
\end{abstract}

Meningiomas are the second most common brain tumours in adults, arising from the arachnoid cells of the meninges. They account for approximately one third of all primary intracranial tumours. Meningiomas have a female predominance as they are twice as common in women as in men. The incidence rises with age and the tumors are most common in middle-aged or

This article is freely accessible online.

Correspondence to: Mr. Richard W. Gullan, Department of Neurosurgery, King's College Hospital, London SE5 9RS, U.K. Tel: +44 02032993117, e-mail: Richardgullan@kch.nhs.net

Key Words: SPARC, invasion, meningioma, immunohistochemistry, malignant, recurrence. elderly people. It is higher after the fifth decade and peaks in the sixth and seventh decade. Indeed, a substantial portion remain unnoticed or are detected at autopsy alone. Long-term prognosis for cranial meningiomas is generally good as the overall 5-year survival is reported to be over $80 \%$ (1-3).

Grade I meningiomas are typically benign and noninvasive, based on their histological characteristics. These slow growing neoplasms are usually resected surgically. In higher grades of meningiomas, if invasion of the adjacent bone occurs, it is not always possible to remove it completely. The probability of recurrence in Grade II (atypical) and III (malignant) meningiomas is dependent on various factors including invasion into the parenchyma of the brain.

According to the previous World Health Organization (WHO) classification, 2007, Grade I (benign) meningiomas have a low risk of recurrence and aggressive growth with 22 subtypes. Grade II (atypical) meningiomas are more likely to recur whilst Grade III (anaplastic) meningiomas have the greatest likelihood of recurrence and/or are more aggressive (4). However, the current WHO Classification (2016) has included brain invasion as a grading criterion for atypical meningiomas, Grade II (5). Moreover, atypical meningiomas can also be diagnosed on the basis of 3 out of 5 additional criteria of histological features: mitosis, spontaneous necrosis, hypercellularity, small cell formation and sheeting architecture.

Invasion is defined as penetration of the brain parenchyma by nests of meningioma cells. As with gliomas, infiltrative invasion into the contiguous brain is also considered to be a vital step of tumour progression and indeed recurrence in meningiomas. Extracellular matrix (ECM) proteins are thought to play an important role in invasive meningiomas and in progression to malignancy. We have previously studied a battery of matrix metalloproteinases (MMPs) and ADAMs (a disintegrin and metalloproteinase) in meningiomas which are implicated as mediators of invasion 
(6). We suggested that elevated gene expression patterns of these proteins may also indicate biological progression and recurrence.

It is important to understand how cancer cells interact with their microenvironment in order to elucidate pathways that control tumour growth, invasion and progression (7-10). The tumour microenvironment comprises tumour cells, ECM, pericytes, fibroblasts, endothelial cells and resident leukocytes (11). ECM is a remodelling network which not only provides a structural framework for cells but also regulates proliferation, migration, survival etc. In turn, it is regulated by matricellular proteins (a functional family of extracellular proteins). An example of the latter is secreted protein, acidic and rich in cysteine (SPARC) which is a multifunctional glycoprotein. It is also known as basement membrane - 40 (MB-40) or osteonectin (12) and is secreted by endothelial cells.

The role of SPARC in tumourigenesis is somewhat paradoxical. It is reported to have a role in multiple biological functions including proliferation, cell adhesion, migration, invasion, angiogenesis and apoptosis. The differential expression of SPARC in tumours and its surrounding stroma in various cancers is well documented. It appears that in some types of cancers, it functions as a tumour suppressor whilst in others it is a tumour promoter. Low levels of SPARC expression in neuroblastomas, leukaemia, ovarian, pancreatic and colorectal cancers support the former whereas higher levels seen in gliomas, breast cancers and melanomas support the latter (13-16).

Rempel and colleagues have extensively studied the overexpression of SPARC in gliomas, particularly earlier studies in the tumour/brain interface which implicated its role in invasion (17) and delayed tumour growth (18). They also investigated various signal pathways involved (19-21). Furthermore, they first suggested that SPARC was a potential diagnostic marker of invasive meningiomas as it was expressed in the invading edge of infiltrating recurrent meningiomas but lacking in non-invasive ones (22). However, in comparison to gliomas, expression of SPARC in meningiomas has not been that well studied.

With changes in WHO classification (2007 and 2016) regarding atypical meningiomas and invasion, some Grade I meningiomas which were seemingly benign with invasive potential are now included in the Grade II category (5). It is of interest to re-evaluate previous lack of SPARC expression with benign meningiomas under the current WHO classification.

The aim of this study was to investigate if there is still a correlation between the grade of meningiomas and immunohistochemical expression of SPARC in a series of meningiomas which were previously classified as Grade I or Grade II, with and some without invasion. To further assess any correlation with recurrence, some patients were followedup as long as possible, up to 14 years after diagnosis.

\section{Materials and Methods}

Tissue specimens. Surgical samples from patients with meningiomas of different grades were obtained from the neurosurgical staff of King's College Hospital, London. At the time of neurosurgery, written informed consent was obtained from 34 patients. This study was approved by the Ethical Committee of King's College Hospital (LREC no: 00-173). The specimens were selected from biopsies collected between 1985 and 2001 .

Clinical and pathological features. All resected specimens were fixed in formalin and embedded in paraffin for pathological diagnosis. The tumour site of the samples included olfactory groove, parasagittal, frontal, parietal, occipital as well as sphenoid wing. The 34 samples used in this study were diagnosed twice; initially according to the 2002 WHO criteria (23) and then the revised 2007 WHO criteria (4) and then further re-diagnosed using the 2016 criteria (5) by a neuropathologist with respect to invasion in Grade II meningioma. The main clinicopathological data are summarised in Table I. Of the 34 selected patients, there were 13 males and 21 females between the ages of 21 and 84 with a mean age of 62 . There were 7 patients diagnosed with Grade I (4 of which had the fibroblastic subtype), 26 with Grade II, atypical and 1 with Grade III, malignant meningioma.

Immunohistochemistry (IHC). Paraffin-embedded sections $(7 \mu \mathrm{m})$ were stained with H\&E (Haematoxylin and Eosin) for routine histopathological evaluation. In addition, immunohistochemical analysis for expression of SPARC was also carried out. Briefly, formalin fixed, paraffin-embedded sections were subjected to deparaffinisation followed by rehydration with xylene and ethanol, respectively, at room temperature. The endogenous peroxidase activity was blocked by immersing the slides in 3\% hydrogen peroxide in methanol for $10 \mathrm{~min}$. The sections were then heated in a microwave oven in a preheated citrate buffer pH6 and then cooled for $20 \mathrm{~min}$. Then they were rinsed in phosphate buffered saline (PBS) solution and incubated with normal sheep serum (Sigma Aldrich, Gillingham, Dorset, UK) for $20 \mathrm{~min}$.

The sections were incubated overnight at $4{ }^{\circ} \mathrm{C}$ with the primary anti-SPARC antibody (Invitrogen, Camarillo, CA, USA) in a 1:1,000 dilution. After three washes with PBS buffer, they were incubated with biotinylated anti-mouse secondary antibody (1:400) for $45 \mathrm{~min}$. Then the sections were finally developed with DAB (3, 3'-diaminobenzidine), rinsed and mounted. Negative control sections were incubated with phosphate buffered saline (PBS) or with irrelevant IgG monoclonal antibody. A neuropathologist blindly reviewed each section and graded the staining intensity as negative (-ve), weak positivity $(+)$, moderate positivity $(++)$ and strong positivity (+++).

Later, when the proliferative maker, Ki67, was included for routine histological diagnostics purposes in our laboratories, it was possible to include only the latter 9 cases out of the 34 selected for it. This immunohistochemistry analysis was used to check for any correlation with recurrence of the tumour assessed clinically. Although, all patients were usually followed-up, some of them for had subsequently been transferred to other hospitals for various reasons. So, for this study, only 11 out of 34 patients were followedup over a period of several years after diagnosis with respect to recurrence. 
Table I. Clinical data, anatomical site and WHO classification of 34 meningioma cases studied.

\begin{tabular}{|c|c|c|c|c|c|c|}
\hline Case & Age & Gender & Anatomical site & Histological subtype & Grade WHO 2016 & Grade WHO 2000 \\
\hline$[\mathrm{S} 01]$ & 54 & $\mathrm{~F}$ & Olfactory groove & Meningioma & I & \\
\hline [S02] & 34 & $\mathrm{~F}$ & Parasagittal & Fibroblastic & I & \\
\hline [S03] & 38 & $\mathrm{~F}$ & R Cerebellopontine Angle & Meningioma & I & \\
\hline [S04] & 69 & $\mathrm{~F}$ & Subfrontal & Meningioma & I & \\
\hline [S05] & 51 & $\mathrm{~F}$ & Frontal & Fibroblastic & I & \\
\hline [S06] & 76 & $\mathrm{~F}$ & Parietal & Fibroblastic & I & \\
\hline [S07] & 21 & M & Intracranial NOS & Fibroblastic & I & Invasive \\
\hline [S08] & 65 & $\mathrm{~F}$ & R Fronto-parietal & Atypical & II & I \\
\hline [S09] & 66 & M & Intracranial NOS & Atypical & II & \\
\hline$[\mathrm{S} 10]$ & 68 & $\mathrm{~F}$ & R Parietal convexity & Atypical & II & \\
\hline$[\mathrm{S} 11]$ & 74 & M & $\mathrm{R}$ sphenoid wing & Atypical & II & \\
\hline$[\mathrm{S} 12]$ & 53 & M & L Fronto-parietal & Atypical & II & \\
\hline [S13] & 76 & M & L Parasagittal & Atypical & II & \\
\hline [S14] & 52 & M & $\mathrm{R}$ Parieto-occipital & Atypical & II & \\
\hline [S15] & 80 & $\mathrm{~F}$ & L Parietal & Atypical & II & \\
\hline [S16] & 54 & $\mathrm{~F}$ & L Frontal & Atypical & II & Invasive \\
\hline$[\mathrm{S} 17]$ & 78 & M & L Fronto-parietal & Atypical & II & Invasive \\
\hline [S18] & 70 & $\mathrm{~F}$ & R Frontal & Atypical & II & \\
\hline [S19] & 73 & M & L Frontal parasagittal & Atypical & II & \\
\hline [S20] & 82 & $\mathrm{~F}$ & R Frontal & Atypical & II & \\
\hline$[\mathrm{S} 21]$ & 73 & M & R Frontal & Atypical & II & \\
\hline$[\mathrm{S} 22]$ & 52 & $\mathrm{~F}$ & R Parietal parasagittal & Atypical & II & \\
\hline [S23] & 79 & M & L Frontal parasagittal & Atypical & II & \\
\hline [S24] & 78 & $\mathrm{~F}$ & Parasaggital & Atypical & II & III \\
\hline$[\mathrm{S} 25]$ & 62 & $\mathrm{~F}$ & Fronto-parietal & Atypical & II & I \\
\hline [S26] & 45 & F & Olfactory groove & Atypical & II & $\mathrm{I}$, invasive \\
\hline$[\mathrm{S} 27]$ & 60 & M & R Parasagittal & Atypical & II & I, invasive \\
\hline [S28] & 47 & $\mathrm{~F}$ & R Occipital & Atypical & II & $\mathrm{I}$, invasive \\
\hline [S29] & 84 & M & L Fronto-temporal & Atypical & II & $\mathrm{I}$, invasive \\
\hline$[\mathrm{S} 30]$ & 61 & M & R Parasagittal & Atypical & II & I, invasive \\
\hline$[\mathrm{S} 31]$ & 58 & $\mathrm{~F}$ & Frontal & Atypical & II & $\mathrm{I}$, invasive \\
\hline$[\mathrm{S} 32]$ & 77 & F & L Frontal & Atypical & II & $\mathrm{I}$, invasive \\
\hline [S33] & 71 & F & Frontal & Atypical & II & \\
\hline [S34] & 43 & F & R Sphenoid wing & Malignant & III & III, Non-invasive \\
\hline
\end{tabular}

L: Left, R: right, NOS: not otherwise specified. The last column reflects previous WHO classification (2000) if different from current one (2016).

\section{Results}

Table I shows the clinical data, anatomical site and WHO classification grades of the 34 meningioma patients in this study. They underwent neurosurgery at King's College Hospital, London, between 1985 and 2001. According to the earlier WHO criteria (2000), there were 17 patients with Grade I (benign, 9 non-invasive and 8 invasive), 15 with Grade II (atypical, 6 noninvasive and 9 invasive) and 2 with Grade III (malignant, 1 noninvasive and linvasive). However, it was deemed necessary to re-classify this cohort of patients as some of them were still being followed-up after 2007. This time, the numbers of patients in Grades I, II and III changed to 7, 26 and 1, respectively (Table I) under the WHO 2007 classification which considers all brain-invasive meningiomas as WHO Grade II. Subsequently, there were no further changes in these groups since the current WHO classification (2016) for meningiomas did not undergo revision, apart from the introduction of brain invasion as a stand-alone criterion for the diagnosis of WHO Grade II, atypical meningioma. For comparison purposes, the last column in Table I was included to reflect changes in 14 out of 34 cases between current WHO classification and that of 2000 e.g. cases [S25-S32] were diagnosed as Grade I previously but as Grade II in 2007 and 2016.

Table II show that these 34 cases were put into 5 categorises: group 1 had 7 benign meningiomas, groups 2, 3 and 4 were all atypical meningiomas with 10,7 and 9 cases, respectively whilst group 5 only had 1 malignant meningioma. Histological criteria of invasion (H\&E) for atypical meningiomas also used in the past include the presence of 3 of 5 histological features: macronuclei, spontaneous necrosis, hypercellularity, small cell formation and sheeting architecture. In addition, the neuropathologist's diagnosis included cords or nests of tumour cells invading brain parenchyma as a feature. 
Table II. SPARC expression using immunohistochemistry in 5 groups of meningiomas studied.

\begin{tabular}{|c|c|c|c|c|c|c|c|c|}
\hline \multirow[t]{2}{*}{ Case no. } & \multirow[t]{2}{*}{ Diagnosis } & \multirow[t]{2}{*}{ Grade } & \multirow{2}{*}{$\begin{array}{c}\text { Invasion } \\
(\mathrm{H}+\mathrm{E})\end{array}$} & \multirow{2}{*}{$\begin{array}{c}\text { *Grade II defined } \\
\text { only by invasion }\end{array}$} & \multicolumn{2}{|c|}{ Staining (SPARC) } & \multirow[t]{2}{*}{ Ki67 expression } & \multirow[t]{2}{*}{ Follow-up } \\
\hline & & & & & Tumour & Margin & & \\
\hline \multicolumn{9}{|l|}{ Group 1} \\
\hline [S01] & Meningioma & I & No & & $\begin{array}{c}\text { Focal +++ } \\
\text { (especially edge) }\end{array}$ & & & \\
\hline [S02] & Fibroblastic & I & No & & $-v e$ & & & \\
\hline$[\mathrm{S} 03$ & Meningioma & I & No & & Diffuse +++ & & & \\
\hline [S04] & Meningioma & I & No & & -ve & & Mod & \\
\hline [S05] & Fibroblastic & I & No & & Focal ++ & $++($ interface $)$ & & \\
\hline [S06] & Fibroblastic & I & No & & -ve & & & \\
\hline [S07] & Fibroblastic & I & No & & Focal ++ (edge) & & & \\
\hline \multicolumn{9}{|l|}{ Group 2} \\
\hline [S08] & Atypical & II & No & N/A & -ve & & & \\
\hline [S09] & Atypical & II & No & N/A & $+/-$ blood vessels & & Mod & \\
\hline$[\mathrm{S} 10]$ & Atypical & II & No & N/A & Focal +++ & $+++($ interface $)$ & & \\
\hline [S11] & Atypical & II & No & N/A & $\begin{array}{c}\text { Focal +++ } \\
\text { (especially edge) }\end{array}$ & & & \\
\hline [S12] & Atypical & II & No & N/A & $-v e$ & & & Recurrence \\
\hline [S13] & Atypical & II & No & N/A & Focal + & & & \\
\hline [S14] & Atypical & II & No & N/A & Focal +/++ & & & Recurrence \\
\hline [S15] & Atypical & II & No & N/A & -ve & & & \\
\hline$[\mathrm{S} 16]$ & Atypical & II & No & N/A & Focal +++ & +++ & $13 \%$ & Recurrence \\
\hline$[\mathrm{S} 17]$ & Atypical & II & No & N/A & -ve & & & Recurrence \\
\hline \multicolumn{9}{|l|}{ Group 3} \\
\hline$[\mathrm{S} 18]$ & Atypical & II & Yes & No & Focal + & & $7 \%$ & Recurrence \\
\hline [S19] & Atypical & II & Yes & No & Focal +++ & Invasive bulges $++/+++$ & $10 \%$ & Recurrence \\
\hline$[\mathrm{S} 20]$ & Atypical & II & Yes & No & Focal + & + (nests) & focal & \\
\hline [S21] & Atypical & II & Yes & No & Focal + & +/- (invasive nests) & $\begin{array}{l}\text { Mod but foci } \\
\text { of high } \\
\text { activity }\end{array}$ & \\
\hline$[\mathrm{S} 22]$ & Atypical & II & Yes & No & Focal +++ & +/++ (nests) & $2-3 \%$ & \\
\hline [S23] & Atypical & II & Yes & No & Focal +++ & $+($ interface $)$ & & Recurrence \\
\hline$[\mathrm{S} 24]$ & Atypical & II & Yes & No & Focal +++ & +/++ (nests) & & \\
\hline \multicolumn{9}{|l|}{ Group 4} \\
\hline$[\mathrm{S} 25]$ & *Atypical & II & Yes & Yes & Focal +++ & +++ (interface) & & \\
\hline$[\mathrm{S} 26]$ & *Atypical & II & Yes & Yes & Diffuse +++ & +++ & & Recurrence \\
\hline [S27] & *Atypical & II & Yes & Yes & Focal +++ & +++ (nests) & & \\
\hline [S28] & *Atypical & II & Yes & Yes & Focal +/++ & + (bulges) & & \\
\hline [S29] & *Atypical & II & Yes & Yes & Focal +++ & +++ (nests) & & \\
\hline [S30] & *Atypical & II & Yes & Yes & Focal +/++ & & & Recurrence \\
\hline$[\mathrm{S} 31]$ & *Atypical & II & Yes & Yes & Focal++ & & & \\
\hline$[\mathrm{S} 32]$ & *Atypical & II & Yes & Yes & -ve & & & Recurrence \\
\hline [S33] & *Atypical & II & Yes & Yes & Focal +++ & +++ (invasive nests) & & \\
\hline $\begin{array}{l}\text { Group } 5 \\
{[\text { S34] }}\end{array}$ & Malignant & III & No & No & $\begin{array}{c}\text { Focal +++ } \\
\text { (especially edge) }\end{array}$ & & $\begin{array}{c}20-30 \% \\
\text { very high }\end{array}$ & Recurrence \\
\hline
\end{tabular}

*Refers to Atypical Grade II meningiomas which are put into this category solely because of the identification of brain invasion and not by other histological criteria. Staining: - ve=negative, $+=$ weak positivity, $++=$ moderate positivity, $+++=$ strong positivity.

The immunohistochemistry results for SPARC staining in Table II show that in group 1, of the 7 cases of Grade I meningiomas (with no invasion), 1 had diffuse strong positivity, 1 had focal strong positivity, especially at the edge of the tumour, 2 had moderate and 3 had none in the tumour. Case [S05] also had moderate positivity at the interface.

Of the 10 Grade II atypical meningiomas with no invasion (H\&E) in the second group, 3 had strong focal positivity, 1 
A

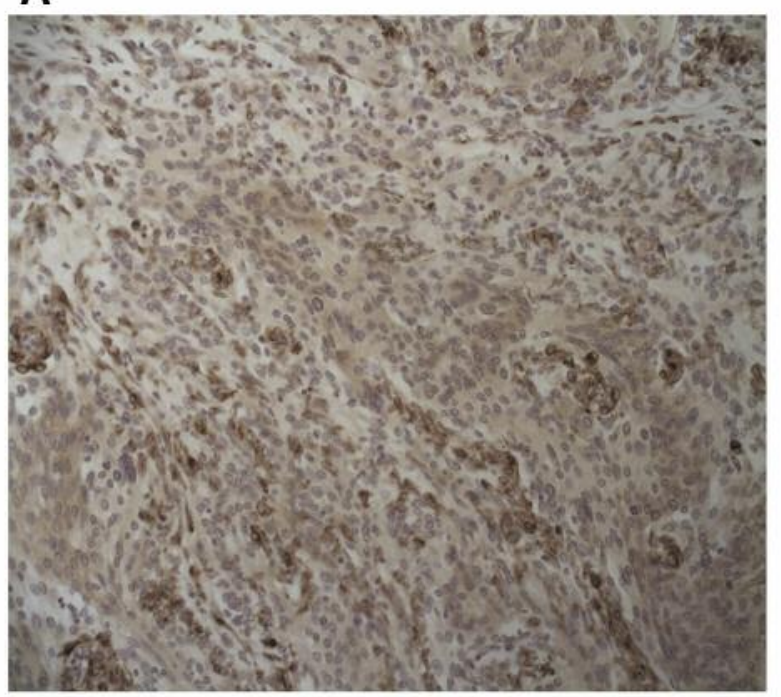

C

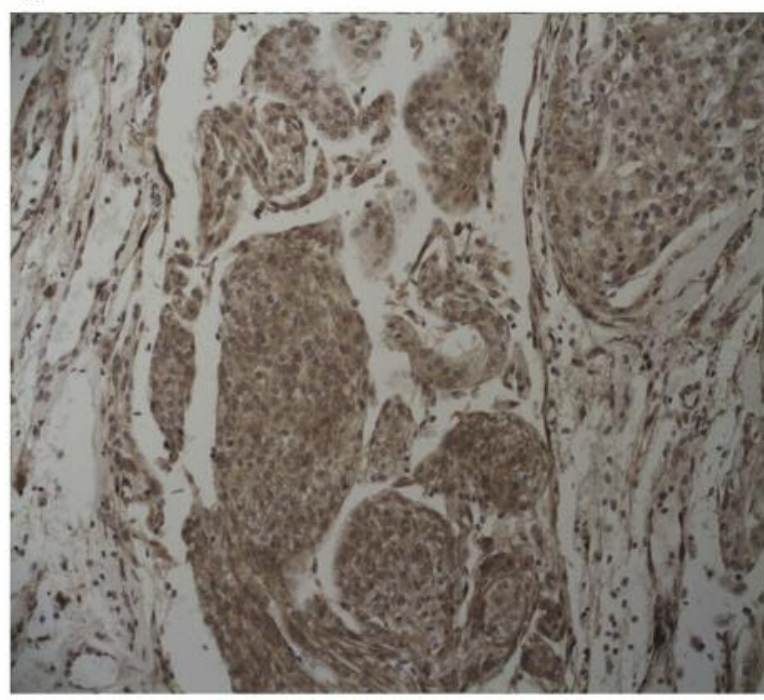

B

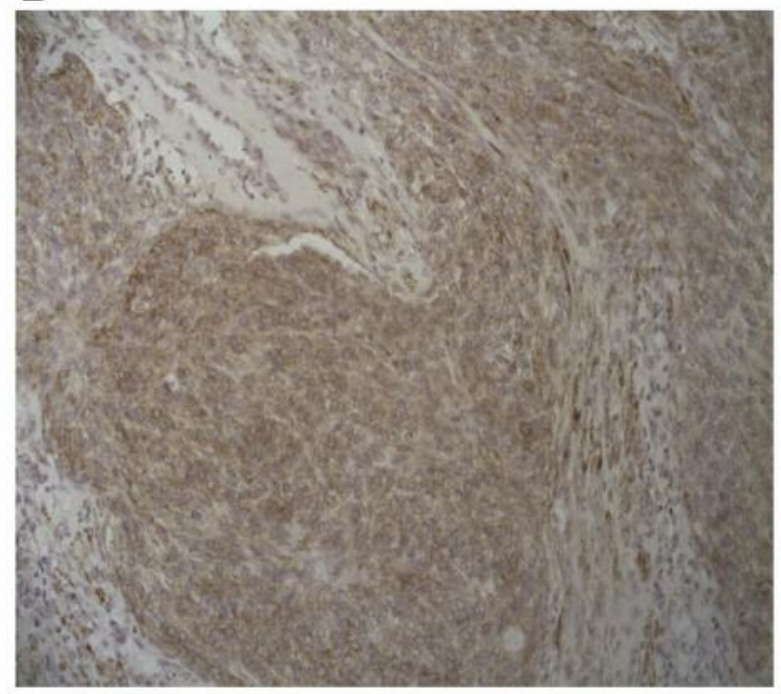

D

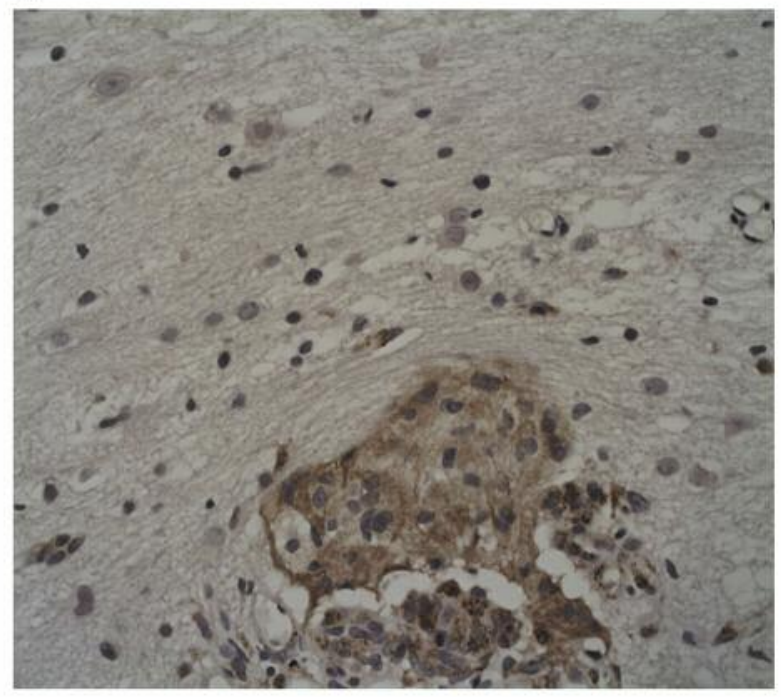

Figure 1. Representative SPARC expression by immunohistochemistry in 4 cases of Grade II atypical meningioma. (A) Case [S10] (Group 2), no invasion seen but very strong focal SPARC staining in tumour and interface $\times 20$ magnification. (B) Case [S24] (Group 3) meningioma with invasion, very strong focal SPARC staining in tumour and strong staining (nests) at interface $\times 20$ magnification. (C) Case [S26] (Group 4) meningioma with invasion, very strong diffuse SPARC staining in tumour and margin $\times 20$ magnification. (D) Case [S27] (Group 4) meningioma with invasion, very strong staining at interface (nests) $\times 40$ magnification.

weak/moderate in the tumour, 2 weak positivity and 4 were negative. Two of them ([S10] and [S16]) also had strong positivity in the interface. Figure $1 \mathrm{~A}$ illustrates this both in the tumour and the interface for case [S10]. In group 3, of the 7 Grade II cases with invasion demonstrated on H\&E but not seen on SPARC sections, 4 had strong positivity whereas the other 3 had weak positivity in the tumour. All of them showed positivity in the tumour margin as well. [S19] had moderate to strong positivity bulges whilst others had either weak or strong positivity in the nests for 4 cases: [S20], [S21], [S22] and [S24] (Figure 1B).

For this study patients in group 4 (*atypical meningiomas) were put into this category solely because of the identification of brain invasion and not by other histological criteria. The 9 cases in this group with invasion, demonstrated both on H\&E and SPARC sections had focal strong positivity in the tumour in 4 of them, weak to moderate focal in 2 cases and no positivity in one. Diffuse strong positivity was seen in 1 case. 
In 3 cases ([S27], [S29] and [S33]), the invasive nests also showed strong positivity. Figure 1C shows very strong diffuse positivity for SPARC in case [S26] in the tumour and the margin whereas Figure 1D illustrates very strong staining in the nests at the interface. The last group comprised only 1 case (Grade III) with no invasion but strong focal positivity in the tumour, especially at the edge.

Collectively, out of the 34 cases studied, 8 benign and 5 atypical meningiomas showed no expression of SPARC at all. This suggests a lack of correlation between SPARC expression and invasive potential of meningiomas.

The proliferative marker Ki67/MIB-1 which is associated with risk of recurrence was only tested in 9 out of 34 cases when introduced as routine histological diagnosis (Table II). In group 1, Ki67 was moderately expressed in one benign meningioma [S04]. One of 2 atypical meningiomas in group 2 [S09] had shown moderate expression of this marker whilst the second case [S16] had 13\% Ki67 expression which correlated with recurrence 2 years after first diagnosis. In this group, tumour recurrence was noted in 4 out of 10 cases, at various times. In group 3,5 out of 7 cases had low/moderate expression of the proliferative marker. In cases [S18] and [S19] expression of $\mathrm{Ki} 67$ at $7 \%$ and 10\% respectively correlated with recurrence seen 2 years after diagnosis. In group 4, 3 out of 9 showed tumour recurrence. In the last group, the malignant meningioma [S34] had the highest Ki67 expression (20-30\%) as well as recurrence.

\section{Discussion}

Although benign meningiomas (Grade I) grow slowly by expansion, some of them have invasive potential and are known to invade not only brain parenchyma but also bone. This is due to their ability to extend into mesenchymal tissue. Clinical considerations and impact on neuropathological evaluation of brain invasion in meningiomas has been reviewed by other workers (24). Histologically, the definition of brain invasive growth previously was "the presence of meningioma tissue within adjacent brain without a separating connective tissue layer" (25). Brain invasion has also been defined frequently according to the distinct infiltrative growth pattern of "tongue- or finger-like protrusion of the tumour into the adjacent brain tissue" (26-28). Others have reported diffuse (single cell spreading) (29) or cluster-like invasion (clustered "nests/islands of tumour cells" into the adjacent brain parenchyma (30).

Since the pioneering work of Perry and co-workers (25) gave the first definition of invasive growth over 2 decades ago, the stand-alone criterion for atypical meningiomas for histopathological grading is brain invasion. In this study, some of the cases which were considered according to WHO classification to be benign meningiomas in 2000 (23) had been re-classified subsequently as atypical (Grade II) in 2007
(4) with very little change for these neoplasms in 2016 (5). Hence the meningiomas studied were predominantly atypical. Obviously, the changes in the WHO criteria and reassigning of grades, has resulted in increased diagnosis of atypical meningiomas.

Trying to compare our results with data from retrospective studies which used older WHO criteria may not be applicable or appropriate. Additionally, sometimes results based on different methods of analysis, groups of samples or tissue type (e.g. paraffin sections or cultured cells etc.) are difficult to compare as this may lead to contradictory conclusions.

There is ample data on SPARC and other cancers (13-16) as well as gliomas (16-21) in the literature but very few studies have been reported its significance in invasive and/or recurrent meningiomas. This study showed that positive staining for SPARC to some degree was detected in 4 out of 7 benign meningiomas in group 1 with no invasion (H\&E). In the 3 categories of Grade II meningiomas, there was no expression of SPARC in 5 out of 26 cases. The above mentioned contributing factors (WHO reclassification and/or methodology) may explain why our results from SPARC immunohistochemistry do not agree with one of the earliest studies by Rempel et al. (22). Unlike us, they compared 2 groups of meningiomas: nonrecurrent ( 9 Grade I, non-invasive) with recurrent (9 Grade I, II and III, invasive). SPARC was expressed in the invading edge of infiltrating meningiomas in the latter group and they suggested this multifunctional protein was a potential diagnostic marker of invasion. Moreover, Rempel's study of 29 cases (1999) was based not only on the older WHO classification of 1993 but could have also reflected a natural variation in population. The key factors which differentiate their study from ours (based on the latest WHO classification) is probably the activity of the SPARC protein and that invasiveness might depend on ECM. Indeed, if invasion is close to the leptomeninges or further away from it, there is likely to be variability of ECM proteins depending on its location. Additionally, SPARC could be a transient marker related to cell cycle or ECM proteins. Nonetheless, it is not known if invasion is linked to any proteins.

Later, another group, using the WHO classification criteria of 2000 looked at patterns of SPARC expression at the tumour-brain border in 51 brain-invasive meningiomas ( 31 Grade I, 11 Grade II and 9 Grade III) (31). It is likely that under the current classification, some of the Grade I meningiomas they studied were really Grade II. However, our findings are consistent with theirs as SPARC expression was found in tumour cells and not just restricted to the tumour-brain border as well as non-invasive and invasive meningiomas. However, they saw diffuse cytoplasmic labelling of the tumour mass in contract to our results which showed focal staining. In agreement with their suggestion, 
our findings do not support the notion that SPARC is a prognostic or universal marker for distinguishing meningiomas which are either brain-invasive or noninvasive. Mawrin et al. (32) have shown that SPARC was increased in aggressive meningiomas but they used different techniques as well as cell lines (in vitro) and therefore not entirely comparable to the present study. They have also highlighted in a relatively more recent systematic review (33) the impact of histological grading in the WHO classification of meningiomas since 1979.

At the time of collection of the first samples for this study in 1985, the proliferative marker, Ki67/MIB-1 was not included routinely in our Neuropathology diagnostic laboratories, but introduced much later. Subsequently, only 9 out of 34 cases were stained with Ki67 for histological diagnosis. Another finding from our study, (albeit with limited data) was that the expression of this proliferative marker showed some correlation with recurrence. Other studies have associated Ki67 expression with risk of recurrence. It has become an important diagnostic and prognostic tool for the identification of aggressive meningiomas $(34,35)$.

It is considered that the presence of brain invasion predicts aggressive clinical behaviour and recurrence in meningiomas. The recurrence rate, after complete resection is approximately $10-32 \%$ within 10 years. In terms of clinical outcome, it was possible to follow-up only some of the patients in this study for various reasons (e.g. the patient was transferred to another hospital). Recurrence was noted (Table II) in approximately one third of patients (10 Grade II and 1 Grade III). The first of these 11 patients in Group 2 (Table II) was a 53-year-old male [S12] who underwent a left frontoparietal craniotomy and excision of meningioma in 1998. Ten years later, some recurrence was seen on CT scan and noted to be slow-growing. No further surgery was recommended. The next patient was a 52 year old male [S14] who previously had craniotomy for right parieto-occipital meningioma in 1995. Fourteen years later, in 2009, a small volume of residual/recurrence was seen on the follow-up scans. Again, no surgery was done this time. The third patient [S16] was a 54-year-old female whose first surgery was in 1998 to excise a left frontal meningioma. She underwent a second surgery 2 years later due to a large recurrent bilateral parasagittal tumour which showed widespread infiltration of dura in the biopsy report. The next patient [S17] was a 78-year-old male who was diagnosed with a left fronto-parietal meningioma in 1998. Recurrence was seen on CT scans 4 years later but no surgery or radiotherapy was deemed necessary.

The fifth patient [S18] from group 3 (Table II) was a 70year-old male with a right frontal meningioma excised in 2000. There was a bilateral hemisphere involvement noticed on follow-up scans, 4 years later, suggesting recurrence but was considered to be inoperable. A 73-year-old male [S19] had left frontal parasagittal meningioma resected in 2000 . Within 2 years, he had a large recurrence which extended to the corpus callosum. The seventh patient was a 79-year-old male [S23] who had debulking surgery for left frontal parasagittal meningioma. Extensive tumour recurrence was seen in the CT scans 2 years on.

In Group 4, a 45-year-old female [S26] had a total resection for a large olfactory grove meningioma in 1985 . She had recurrence 10 years later which was excised again. In 1997 (12 years on), there were small recurrences in 2 areas separated by infiltrated dura. This was not considered to be malignant as it was classified as Grade I then. In 2003, she underwent a third frontal craniotomy and survived another 3 years. The ninth patient [S30] was a 61-year-old male who had his first surgery in 1998 for excision of right parasagittal meningioma. He had an elective resection for recurrent meningioma in 2011. The tenth patient [S32] was a 77-year-old female with a large frontal meningioma which was excised but it recurred 3 years later.

The eleventh patient from Group 5 [S34] was a 43-yearold female who had surgical resection for right sphenoid wing meningioma (Grade III) in 2000, followed by Gamma knife in 2004, further resection for recurrence in 2012 and repeat Gamma knife in 2014, fourteen years after first diagnosis.

It is noteworthy that no recurrence was seen in any of the benign meningiomas (Grade I) as expected. Moreover, 3 of the atypical meningiomas ([S12], [S17] and [S32]) which showed recurrence did not express SPARC. It can be concluded that SPARC does not appear to be a good predictor of invasion in meningiomas in the histological sections studied. The SPARC results did not differentiate between grades. Further studies include evaluating other possible diagnostic and prognostic factors, as well are associated with invasion and recurrence in a larger cohort of patients. Additionally, DNA methylation profiling for meningiomas (36) has been proposed as a more powerful predictor of clinical behaviour than the current WHO classification. It has been suggested that this approach may identify patients who could have benign tumours according to WHO criteria, but who have a high risk of rapid recurrence. The relationship between SPARC expression and methylation classes of meningiomas merits further investigation.

\section{Conflicts of Interest}

Each Author declares that she or he has no conflicts of interest.

\section{Authors' Contributions}

GJP and HKR conceived the study. AJM and UDA conducted the experiments. RWG and NT provided surgical material and clinical updates. AK performed the histological diagnosis, analysis and interpretation of data. HKR wrote the paper. All Authors read and approved the final manuscript. 


\section{Acknowledgements}

The Authors are grateful to the Royal College of Surgeons of England for Mr. Andrew J. Martin's Surgical Research Fellowship and financial support from the late Dennis Roth of Have a Chance, USA. Anna Bolteus is acknowledged for her technical assistance in the laboratory.

\section{References}

1 Perry A, Louis DN, Scheithauer BW, Budka H and Von Deimling A: Meningioma. In: WHO Classifications of Tumours of the Central Nervous System. $4^{\text {th }}$ edition, Louis DN, Ohgaki H, Wiestler OD, Cavenee WK (eds.). International Agency for Research on Cancer, Lyon, pp 164-172, 2007.

2 Love SLouisEllison DW:Greenfield's Neuropathology 8th edition, 2008.

3 Marosi C, Hassler M, Roessler K, Reni M, Sant M, Mazza E and Vecht C: Meningioma. Crit Rev Oncol Hematol 67(2): 153-71, 2008. PMID: 18342535. DOI: 10.1016/j.critrevonc.2008.01.010

4 Louis DN, Ohgaki H, Wiestler OD, Cavenee WK, Burger PC, Jouvet A, Scheithauer BW and Kleihues P: The 2007 WHO classification of the central nervous syste. Acta Neuropathol 114(2): 97-109, 2007. PMID: 17618441. DOI: 10.1007/s00401007-0243-4

5 Louis DN, Perry A, Reifenberger G, von Deimling A, FigarellaBranger D, Cavenee WK, Ohgaki H, Wiestler OD, Kleihues P and Ellison DW: The 2016 World Health Organization classification of tumors of the central nervous system: a summary. Acta Neuropathol 131: 803-820, 2016. PMID: 27157931. DOI: 10.1007/s00401-016-1545-1

6 Rooprai HK, Martin AJ, King A, Appadu UD, Jones H, Selway RP, Gullan RW and Pilkington GJ: Comparative gene expression profiling of ADAMs, MMPs, TIMPs, EMMPRIN, EGF-R and VEGF in low grade meningioma. Int J Oncol 49(6): 2309-2318, 2016. PMID: 27779709. DOI: 10.3892/ijo.2016.3739

7 Lorusso G and Rüegg C: The tumor microenvironment and its contribution to tumor evolution toward metastasis. Histochem Cell Biol 130(6): 1091-1103, 2008. PMID: 18987874. DOI: 10.1007/s00418-008-0530-8

8 Zalatnai A: Molecular aspects of stromal-parenchymal interactions in malignant neoplasms. Curr Mol Med 6(6): 685-693, 2006. PMID: 17022738. DOI: $10.2174 / 1566524067788195053$

9 Liotta LA and Kohn EC: The microenvironment of the tumourhost interface. Nature 411(6835): 375-379, 2001. PMID: 11357145. DOI: $10.1038 / 35077241$

10 Hanahan D and Coussens LM: Accessories to the crime: functions of cells recruited to the tumor microenvironment. Cancer Cell 21(3): 309-322, 2012. PMID: 22439926. DOI: 10.1016/j.ccr.2012.02.022

11 Pietras K and Östman A: Hallmarks of cancer: Interactions with the tumor stroma. Exp Cell Res 316(8): 1324-1331, 2010. PMID: 20211171. DOI: 10.1016/j.yexcr.2010.02.045

12 Framson PE and Sage EH: SPARC and tumor growth: where the seed meets the soil? J Cell Biochem 92(4): 679-690, 2004. PMID: 15211566 . DOI: $10.1002 /$ jcb.20091

13 Arnold SA and Brekken RA: SPARC: a matricellular regulator of tumorigenesis. J Cell Commun Signal 3(3-4): 255-273, 2009. PMID: 19809893. DOI: 10.1007/s12079-009-0072-4
14 Said N and Theodorescu D: Secreted protein acid and rich in cysteine (SPARC) in cancer. J Carcinogene Mutagene 4(3): 151, 2013. DOI: $10.4172 / 2157-2518.1000151$

15 Tai IT and Tang MJ: SPARC in cancer biology: its role in cancer progression and potential for therapy. Drug Resist Update 11(6): 231-246, 2008. PMID: 18849185. DOI: 10.1016/j.drup.2008.08.005

16 Chlenski A and Cohn SL: Modulation of matrix remodelling by SPARC in neoplastic progression. Semin Cell Devel Biol 21(1): 5565, 2010. PMID: 19958839. DOI: 10.1016/j.semcdb.2009.11.018

17 Rempel SA, Golembieski WA, Ge S, Lemke N, Elisevich K, Mikkelsen T and Gutierrez JA: SPARC: A signal of astrocytic neoplastic transformation and reactive response in human primary and xenograft gliomas. J Neuropath Exp Neurol 57(12): 1112-1121, 1998. PMID: 9862633. DOI: 10.1097/00005072-199812000-00002

18 Schultz C, Lemke N, Ge S, Golembieski WA and Rempel SA: Secreted protein acidic and rich in cysteine promotes glioma invasion and delays tumor growth in vivo. Cancer Res 62(21): 6270-6277, 2002. PMID: 12414657.

19 Golembieski WA, Ge S, Nelson K, Mikkelsen T and Rempel SA: Increased SPARC expression promotes U87 glioblastoma invasion in vitro. Int J Devl Neuroscience 17(5-6): 463-472, 1999. PMID: 10571408. DOI: 10.1016/s0736-5748(99)00009-x

20 Golembieski WA, Thomas SL, Schultz CR, Yunker CK, McClung HM, Lemke N, Cazacu S, Barker T, Sage EH, Brodie $\mathrm{C}$ and Rempel SA: HSP27 mediates SPARC-induced changes in glioma morphology, migration, and invasion. Glia 56(10): 10611075, 2008. PMID: 18442089. DOI: 10.1002/glia.20679

21 Alam R, Schultz CR, Golembieski WA, Poisson LM and Rempel SA: PTEN suppresses SPARC-induced pMAPKAPK2 and inhibits SPARC-induced Ser78 HSP27 phosphorylation in glioma. Neuro Oncol 15(4): 451-461, 2013. PMID: 23382286. DOI: $10.1093 /$ neuonc/nos326

22 Rempel SA Ge S and Gutierrez JA: SPARC: A potential diagnostic marker of invasive meningiomas. Clin Cancer Res 5(2): 237-241, 1999. PMID: 10037170.

23 Kleihues P, Louis DN, Scheithauer BW, Rorke LB, Reifenberger G, Burger PC and Cavenee WK: The WHO Classification of Tumors of the Nervous System. J Neuropath Exp Neurol 61(3): 215-225, 2002. PMID: 11895036. DOI: 10.1093/jnen/61.3.215

24 Brokinkel B, Hess $\mathrm{K}$ and Mawrin C: Brain invasion in meningiomas-clinical considerations and impact of neuropathological evaluation: a systematic review. Neuro Oncol 19(10): 12981307, 2017. PMID: 28419308. DOI: 10.1093/neuonc/nox071

25 Perry A, Stafford SL, Scheithauer BW, Suman VJ and Lohse CM: Meningioma grading: an analysis of histologic parameters. Am J Surg Pathol 21(12): 1455-1465, 1997. PMID: 9414189. DOI: $10.1097 / 00000478-199712000-00008$

26 Fritz J, Roser F, Tatagiba M and Bornemann A: The basement membrane at the tumour-brain interface of brain-invasive grade I meningiomas. Neuropathol Appl Neurobiol 31(3): 339-342, 2005. PMID: 15885070. DOI: 10.1111/j.1365-2990.2005.00661.x

27 Zeltner L, Schittenhelm J, Mittelbronn M, Roser F, Tatagiba M, Mawrin C, Kim YJ and Bornemann A: The astrocytic response towards invasive meningiomas. Neuropathol Appl Neurobiol 33(2): 163-168, 2007. PMID: 17359357. DOI: 10.1111/j.13652990.2006.00792.x

28 Backer-Grøndahl T, Moen BH, Arnli MB, Torseth K and Torp $\mathrm{SH}$ : Immunohistochemical characterization of brain-invasive meningiomas. Int J Clin Exp Pathol 7(10): 7206-7219, 2014. PMID: 25400818. 
29 Spille DC, Heß K, Sauerland C, Sanai N, Stummer W, Paulus W and Brokinkel B: Brain Invasion in Meningiomas: Incidence and Correlations with Clinical Variables and Prognosis. World Neurosurg 93: 346-354, 2016. PMID: 27344043. DOI: 10.1016/ j.wneu.2016.06.055

30 Mawrin C and Perry A: Pathological classification and molecular genetics of meningiomas. J Neurooncol 99(3): 379-391, 2010 PMID: 20809251. DOI: 10.1007/s11060-010-0342-2

31 Schittenhelm J, Mittelbronn M, Roser F, Tatagiba M, Mawrin C and Bornemann A: Patterns of SPARC expression and basement membrane intactness at the tumour-brain border of invasive meningiomas. Neuropath and Appl Neurobiol 32(5): 525-531, 2006. PMID: 16972886 . DOI: 10.1111/j.1365-2990.2006.00761.x

32 Mawrin C, Wolke C, Haase D, Krüger S, Firsching R, Keilhoff G, Paulus W, Gutmann DH, Lal A and Lendeckel U: Reduced activity of CD13/aminopeptidase $\mathrm{N}$ (APN) in aggressive meningiomas is associated with increased levels of SPARC. Brain Pathol 20(1): 200-210, 2010. PMID: 19236378. DOI: 10.1111/j.1750-3639.2009.00267.x

33 Brokinkel B, Hess $\mathrm{K}$ and Mawrin C: Brain invasion in meningiomas-clinical considerations and impact of neuropathological evaluation: a systematic review. Neuro Oncol 19(10): 1298-1307, 2017. PMID: 28419308. DOI: 10.1093/neuonc/nox071

34 Torp SH, Lindboe CF, Grønberg BH, Lydersen S and Sundstrøm S: Prognostic significance of Ki-67/MIB-1 proliferation index in meningiomas. Clin Neuropathol 24(4): 170-174, 2005. PMID: 16033133
35 Abry E, Thomassen IØ, Salvesen $\varnothing \mathrm{O}$ and Torp SH: The significance of Ki-67/MIB-1 labeling index in human meningiomas: a literature study. Pathol Res Pract 206(12): 810815, 2010. PMID: 20951502. DOI: 10.1016/j.prp.2010.09.002

36 Sahm F, Schrimpf D, Stichel D, Jones DTW, Hielscher T, Schefzyk S, Okonechnikov K, Koelsche C, Reuss DE, Capper D, Sturm D, Wirsching HG, Berghoff AS, Baumgarten P, Kratz A, Huang K, Wefers AK, Hovestadt V, Sill M, Ellis HP, Kurian $\mathrm{KM}$, Okuducu AF, Jungk $\mathrm{C}$, Drueschler $\mathrm{K}$, Schick $\mathrm{M}$, Bewerunge-Hudler M, Mawrin C, Seiz-Rosenhagen M, Ketter R, Simon M, Westphal M, Lamszus K, Becker A, Koch A, Schittenhelm J, Rushing EJ, Collins VP, Brehmer S, Chavez L, Platten M, Hänggi D, Unterberg A, Paulus W, Wick W, Pfister SM, Mittelbronn M, Preusser M, Herold-Mende C, Weller M and von Deimling A: DNA methylation-based classification and grading system for meningioma: a multicentre, retrospective analysis. Lancet Oncol 18(5): 682-694, 2017. PMID: 28314689. DOI: $10.1016 / \mathrm{S} 1470-2045(17) 30155-9$
Received February 6, 2020

Revised April 23, 2020

Accepted April 29, 2020 